\title{
BONDING IN ALKALI AND ALKALINE EARTH ACETYLACETONATES ${ }^{[a]}$
}

\section{A Festschrift honoring Professor Raymond N. Keller, University of Colorado, Boulder}

\author{
Erwin Boschmann, ${ }^{[\mathbf{b}]}$ R. N. Keller ${ }^{[\mathbf{c}]}$
}

Keywords: Bonding - Alkali Acetylacetonates - Alkaline Earth Acetylacetonates - Chelates Salts

\begin{abstract}
Infrared, ultraviolet, and nuclear magnetic resonance spectroscopies have been used to obtain quantitative data to definitively establish the nature of bonding in alkali and alkaline earth acetylacetonates. Most of these acetylacetonates are salt-like in their behavior; however the properties severat of some lighter metal complexes reflect a covalent ("benzenoid") character. Within a family the change from benzenoid to ionic character is quite abrupt, occurring between lithium and sodium compounds for the alkali metals, and between beryllium and calcium for the alkaline earths, with the magnesium compound being intermediate. The ionic compounds hydrolyze readily unless totally water-free environments are used. The claim of a more covalent structure for the hydrated form, as opposed to the non-hydrated form of a given acetylacetonate is not supported by the results of this study. The order of iconicity, as well as the ease of hydrolysis in common selvents were studied.
\end{abstract}

\section{Introduction}

Chelates (from the Greek $\chi \eta \lambda \eta \dot{n}$, chēlē, meaning "claw") are claw-like structures which have fascinated chemists for well over a century. One of the best known chelating agents is acetylacetone, $\mathrm{C}(\mathrm{O})-\mathrm{CH}_{2} \mathrm{C}(\mathrm{O})-\mathrm{CH}_{3}$, which undergoes chemical reactions with virtually all metals and many metalloids, thus presenting a plethora of colorful research possibilities. An excellent review of its chemistry is given by J.P. Fackler. If ${ }^{[1]}$

[a] Presented in part before the Indiana Academy of Sciences, 1971. See Proceedings, Volume 80, p. 151. Abstracted in part from a thesis submitted by Erwin Boschmann to the Graduate School of the University of Colorado in partial fulfillment for the degree of Doctor of Philosophy, Department of Chemistry, 1968.

[b] Corresponding author Department of Chemistry and Chemical Biology Indiana University Purdue University Indianapolis, IUPUI 402 N. Blackford Street,

Indianapolis, Indiana, USA 46202-3274

Erv@iu.edu

[c] Department of Chemistry, University of Colorado, Boulder, Colorado, USA. Professor Keller is diseased.

This is the author's manuscript of the article published in final edited form as:

Boschmann, E., \& Keller, R. N. (2019). Bonding in alkali and alkaline earth acetylacetonates. Journal of Molecular Structure. https://doi.org/10.1016/j.molstruc.2019.05.131 
Chemists' attention has been focused primarily on the interaction of acetylacetone with transition metals virtually ignoring derivatives of active metals. This is understandable since the former have versatile $d$ electrons at their disposal and thus are potential $\pi$ bonders by either donating or receiving electrons. Acetylacetonates of alkali and alkaline earths, first prepared in the 1880 s, were dismissed as uninteresting simple salts primarily on the basis of physical properties such as solubility, melting point, or color. Even their spectra are quite redundant. Based on these facts, some workers have regarded them as ionic chelates. ${ }^{[2]}$

Nevertheless, the claim has been made that acetylacetonates of lithium, beryllium, and even magnesium ions appear to display some covalent properties. Early references to the fact that in organic solvents the hydrated $\beta$-diketonate of sodium is more soluble than its anhydrous form, is apparently the basis for the erroneous statements in the literature that hydrated chelates have more covalent character than their anhydrous counterparts. ${ }^{[2]}$

The nature of metal-chelate bonding has been investigated most successfully by means of infrared spectroscopy. In 1949 work was begun by Rasmussen, Tunicliff and Brattain, ${ }^{[3]}$ and by Morgan ${ }^{[4]}$ on the infrared absorption of acetylacetone and of its metal derivatives. These studies were continued and extended by many workers and, on the basis of the accumulated IR data, led to some definitive conclusions. ${ }^{[5]}$ Thus, the lowering of the carbonyl vibration frequency in metal chelates as compared to that absorption in acetylacetone itself, is evidence of metal-oxygen bonding, and the shift to higher frequency of the vinyl group carbon-hydrogen stretch upon chelation, have all contributed to the conclusion that transition metal acetylacetonates possess a benzenoid-like structure. ${ }^{[6]}$ It was concluded that as the M-O bond becomes stronger its frequency increases, and the $\mathrm{C}=\mathrm{O}$ bond strength becomes correspondingly weaker showing its absorption at lower frequency. The observation was also made that the methyl group $\mathrm{C}-\mathrm{H}$ stretching frequency is not affected by chelation, whereas the $\mathrm{C}-\mathrm{H}$ stretch of the vinyl group, $=\mathrm{CH}-$, is shifted to a higher frequency upon chelation. ${ }^{[7]}$

Far infrared absorptions for compounds containing M-O bonds were observed as far back as $1949^{[4]}$ but the first systematic investigation by Kazuo-Nakamoto, ${ }^{[8]}$ made the assignment of $\sim 400 \mathrm{~cm}^{-1}$ for the $\mathrm{M}-\mathrm{O}$ stretching vibration for the case of $\mathrm{Cu}(\mathrm{acac})_{2}{ }^{[9]}$

Ultraviolet investigations have focused on the wave length of the absorption maxima of acetylacetonates and have shed some light on the nature of the metal-oxygen bonds. The few reports of studies other than those for $\mathrm{H}(\mathrm{acac})\left[\mathrm{acac}^{-}=\right.$acetylatcetonate], $\mathrm{Be}(\mathrm{acac})_{2}$, and $\mathrm{Mg}(\mathrm{acac})_{2}$, are scattered through the literature ${ }^{[\mathbf{6 , 1 0 , 1 1 ]}}$ and disagree not only in values of extinction coefficients, but also show large discrepancies in the values assigned to absorption maxima.

The earliest paper reporting NMR data on acetylacetonates is that of Holm and Cotton, ${ }^{[6]}$ who in 1958 studied $\mathrm{Be}(\mathrm{acac})_{2}$ and concluded that the vinylic hydrogen, $=\mathrm{CH}-$, resonance shifts provided little evidence for what they called "benzenoid structure." However, later other workers found that changes in the position of vinylic hydrogen vibrational frequency may be attributed to corresponding changes in ring currents. ${ }^{[12,13,14]}$ 
Using both physical and spectroscopic investigations we undertook an orderly study of alkali and alkaline earth ions of both anhydrous and hydrated acetylacetonates to answer these questions:

a. Is the bonding in metal acetylacetonates salt-like, covalent, or both?

b. If several bonding types occur, at what point does a change take place?

c. Is the change, if any, gradual or abrupt?

d. What is the nature of bonding in anhydrous vs. hydrated metal acetylacetonates?

\section{Results and Discussion}

A striking feature of the acetylacetonates of the heavier alkali and alkaline earth metals is the similarity of their IR, their UV, and their NMR absorptions. In the case of IR spectra of the heavier metal compounds this similarity is evident not only in carbonyl and metal-oxygen absorptions, but also in the finer details in the fingerprint region [See Figure 1 and Table I]. And equally striking is the observation that the acetylacetonates of the lighter metals of these groups show very pronounced differences in IR, UV, and NMR absorptions from those of the compounds of the heavier members. In fact, IR features of these lighter acetylacetonate complexes are reminiscent of transition metal acetylacetonate complexes which have been studied since the $1940 \mathrm{~s}$. ${ }^{[5 \mathrm{~b}, 10 \text { and references therein] }}$

\section{$\underline{\text { IR Studies }}$}

These differences in the lighter metal complexes - mainly in the IR carbonyl and metaloxygen absorption peak positions - are directly related to the type of chelate bonding in acetylacetonates. In order for a strong metal-oxygen bond to occur, there must be a corresponding drain of electron density from the $\mathrm{C}=\mathrm{O}$ group into the metal orbitals [this weakens the carbon-oxygen bond and lowers its force constant resulting in a decrease in the carbonoxygen frequency]. Simultaneously the metal-oxygen vibrational frequency increases.

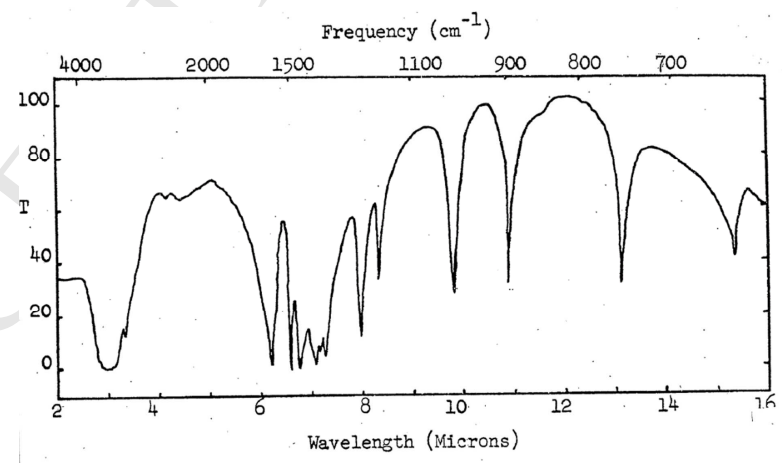

Figure 1. A typical IR spectrum of a petassimm bremide pellet, in this case for $\mathrm{Sr}(\mathrm{acac})_{2} \cdot 2 \mathrm{H}_{2} \mathrm{O}$ in $\mathrm{KBr}$ pellets. 
Table I. IR Absorptions in $\mathrm{cm}^{-1}$ of Anhydrous Metal Acetylacetonates

\begin{tabular}{|c|c|c|c|c|c|c|}
\hline \multirow{2}{*}{$\underline{\text { Alkali }}$} & \multicolumn{2}{|c|}{ Absorption } & \multicolumn{2}{|r|}{$\underline{\text { Alkaline Earth }}$} & \multicolumn{2}{|c|}{ Absorption } \\
\hline & $\mathrm{C}=\mathrm{O}$ & $\mathrm{M}-\mathrm{O}$ & i & & $\mathrm{C}=\mathrm{O}$ & $\mathrm{M}-\mathrm{O}$ \\
\hline $\mathrm{Li}$ & 1585 & 800 & i & $\mathrm{Be}$ & 1571 & 826 \\
\hline $\mathrm{Na}$ & 1621 & 525 & i & $\mathrm{Mg}$ & 1612 & 560 \\
\hline $\mathrm{K}$ & 1620 & 520 & 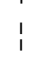 & $\mathrm{Ca}$ & 1602 & 531 \\
\hline $\mathrm{Rb}$ & 1613 & 520 & i & $\mathrm{Sr}$ & 1609 & 528 \\
\hline Cs & 1616 & 520 & 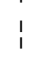 & $\mathrm{Ba}$ & 1602 & 525 \\
\hline
\end{tabular}

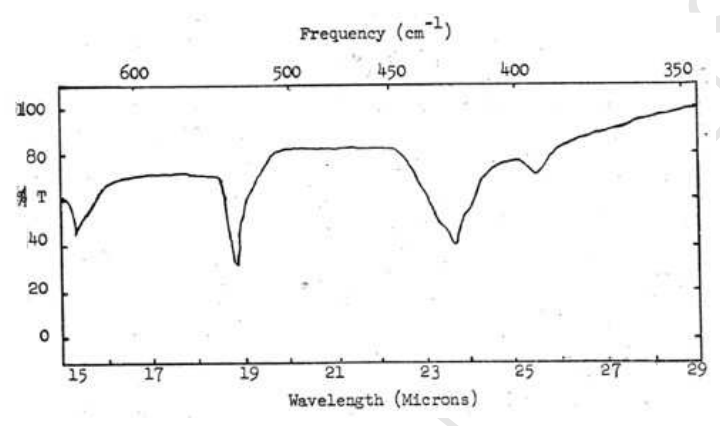

Figure 2. Far IR spectrum of a $\mathrm{KBr}$ pellet of $\mathrm{Sr}(\mathrm{acac})_{2} \cdot 2 \mathrm{H}_{2} \mathrm{O}$ scanned on a Beckman IR-10 Perkin Elmer spectrophotometer.

From Table 1 and Figure 2 it becomes obvious that while the $\mathrm{C}=\mathrm{O}$ absorption frequencies for both metal groups do not show significant change from Cs up to $\mathrm{Na}$ or from $\mathrm{Ba}$ up to $\mathrm{Mg}$, there is a significant drop from the heavier groups to $\mathrm{Li}$ and to Be. Such drop indicates a weakening of the $\mathrm{C}=\mathrm{O}$ bonds, resulting from a drain of electrons out of the $\mathrm{C}=\mathrm{O}$ bond, a concomitant drop in the force constant, which in turn results in lower frequencies. The only way this can occur is with the establishment of a corresponding bond from the oxygen to the metal: $\mathrm{C}=\mathrm{O} \rightarrow \mathrm{M}$.

Similarly, the M-O bonds show little change in their absorption frequencies from Cs up to $\mathrm{Na}$ and from $\mathrm{Ba}$ up to $\mathrm{Ca}$. While there is a slight change in going from $\mathrm{K}$ to $\mathrm{Na}$, the change from $\mathrm{Ca}$ to $\mathrm{Mg}$ is more significant. However, the changes from its heavier family members to $\mathrm{Li}$, and to $\mathrm{Be}$ are significant. Contrary to the $\mathrm{C}=\mathrm{O}$ drops, these are frequency increases resulting from an influx of electrons, a strengthening of the force constant, and therefore an increase in the absorption frequency.

We infer from these observations that the extent of chelation, the merging of the metal into an electronic network, follows this order: $\mathrm{Be}>\mathrm{Li}>\mathrm{Mg}>\mathrm{Na}$, the other metal acetylacetonates being mostly salts. 
Considered in another way, an analysis of the data displayed in Figures 3 and 4 strongly suggest that both $\mathrm{Li}(\mathrm{acac})$ and $\mathrm{Be}(\mathrm{acac})_{2}$, as opposed to the acetylacetonates of the heavier metals of the first two groups, are compounds in which the metal-oxygen bonds arise not merely from electrostatic attraction of a cation for an anion, but also from orbital overlap with electron delocalization - chelation. The acetylacetonates of sodium, potassium, rubidium, cesium, as well as those of magnesium, calcium, strontium, and barium ions all show similar carbonyl and metaloxygen absorption frequencies indicating similar bonding. Here the results of Figures 4 show no distinguishing feature for magnesium.

Changes in size and electronegativity of the central metal ion are part - but certainly only a part - of the cause for observed differences in the $\mathrm{M}-\mathrm{O}$ absorption frequencies exhibited by these compounds. The effect of the interplay of these parameters is reflected, in a qualitative way, by the values of the M-O force constants. Approximate values of these force constants, $k$,

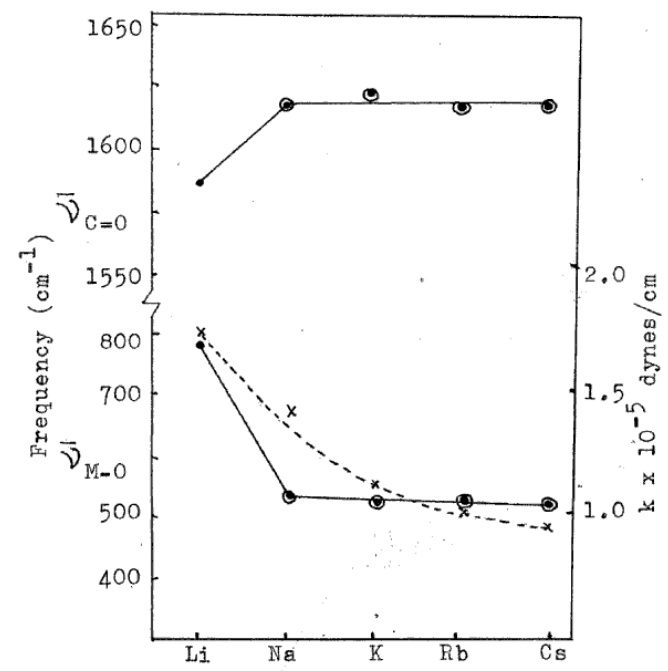

Figure 3. IR stretching frequencies vs. alkali metal acetylacetonates.

- Anhydrous compound

${ }^{\circ}$ Hydrated compound

$\mathrm{x}$ Force constant 


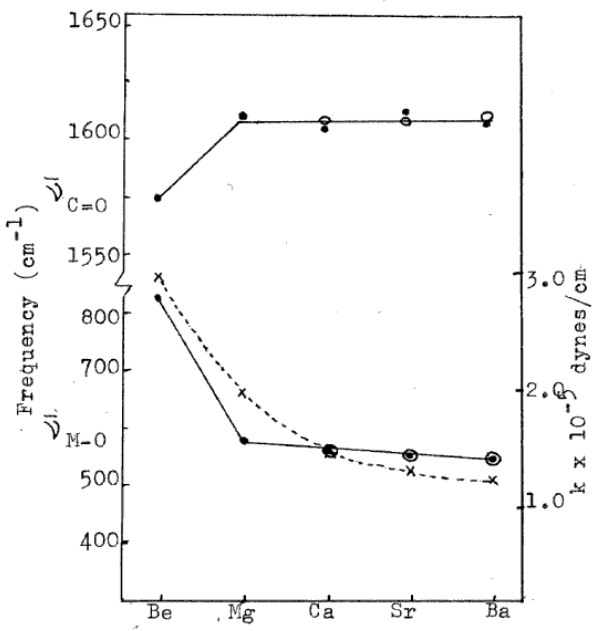

Figure 4. IR stretching frequencies vs. alkaline earth metal acetylacetonates.

- Anhydrous compound

${ }^{\circ}$ Hydrated compound

$\mathrm{x}$ Force constant

have been calculated using Gordy's rule, ${ }^{[15,16]}$ and are also plotted in Figures 3 and 4 . Here, (for acetylacetonates of a given family), the difference between the trends in the values of the M-O force constants and absorption frequencies is clearly brought out. The relatively smooth curve for the calculated force constants is in distinct contrast to the sharp-breaking observed absorption frequency plot. Again, these data lend support to the contention that a change in bonding occurs between the acetylacetonate of lithium and sodium and between beryllium and magnesium.

Specifically, comparing the alkali and alkaline earth acetylacetonate complexes with the transition metal complexes the following observations may be made. First for the heavier metal complexes the bands are markedly similar. Second, upon chelation the $\mathrm{C}=\mathrm{O}$ band shifts from $1600-1620 \mathrm{~cm}-1$ to around $1500 \mathrm{~cm}^{-1}$. And third, the M-O band $520-530 \mathrm{~cm}^{-1}$ shifts to $800-830$ $\mathrm{cm}^{-1}$ upon chelation.

In a carefully designed quantum chemical study of alkaline earth acetylacetonates it has recently been shown ${ }^{[17]}$ (a) that there is a decrease in the M-O bond order, bond length, and electronegativity, a decrease in acetylacetonate stability and covalency from $\mathrm{Be}$ to $\mathrm{Ba}$ complexes; (b) that there is an increase in iconicity from $\mathrm{Be}$ to $\mathrm{Ba}$ acetylacetonate complexes; (c) that the $\mathrm{C}=\mathrm{O}$ bond order increases from $\mathrm{Be}(\mathrm{acac})_{2}$ to $\mathrm{Ba}(\mathrm{acac})_{2}$; and $(\mathrm{d})$ that except for $\mathrm{Be}$ the IR spectra of all complexes are similar to each other. These trends are in agreement with our findings for both the alkali and alkaline earth acetylacetonate complexes.

It is also noteworthy that the absorption frequencies for the anhydrous and hydrated forms of a given acetylacetonate are virtually identical. Since absorption frequency is directly related to the force constant of a given bond, and the latter in turn is related to the electron distribution in the bond, it is clear that the degree of benzenoid-like character is the same among the anhydrous and hydrated forms. Earlier claims concerning $\beta$-diketonate systems ${ }^{[2]}$ are therefore not borne out by the data on acetylacetonates obtained here. 


\section{UV Study}

The UV study was undertaken in the hope that the absorption maxima of these compounds could be correlated with the type of bonding involved. The substantial differences in the values of these maxima, for those compounds which had been reported in the literature, suggested that this approach might be helpful. However, it was soon apparent that measurements involving solutions of the active metal acetylacetonates were complicated by their extreme sensitivity toward hydrolysis. A few tests runs-run at varying concentrations in absolute alcohol made it apparent that discrepancies between published values were due to hydrolysis. In fact, some of the scatter in the values for the molar absorptivities in Table II certainly is a consequence of just such sensitivity.

Table II. UV data for metal acetylacetonates in absolute ethanol

\section{Compound}

$\mathrm{H}(\mathrm{acac})$

$\operatorname{Li}(\mathrm{acac})$

$\mathrm{Na}(\mathrm{acac})$

$\mathrm{K}(\mathrm{acac})$

$\mathrm{Rb}(\mathrm{acac})$

Cs(acac)

$\mathrm{Na}($ acac $) \cdot 2 \mathrm{H}_{2} \mathrm{O}$

$\mathrm{K}(\mathrm{acac}) \cdot 2 \mathrm{H}_{2} \mathrm{O}$

$\mathrm{Rb}$ (acac) $\cdot 2 \mathrm{H}_{2} \mathrm{O}$

$\mathrm{Cs}(\mathrm{acac}) \cdot 2 \mathrm{H}_{2} \mathrm{O}^{*}$ $\underline{\lambda_{\max }} \underline{(\mathrm{m} \mu)}$

292

294

295

295

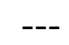

$\mathrm{Be}(\mathrm{acac})_{2}$

$\mathrm{Mg}(\mathrm{acac})_{2}$

$\mathrm{Ca}(\mathrm{acac})_{2}$

$\mathrm{Sr}(\mathrm{acac})_{2}$

$\mathrm{Ba}(\mathrm{acac})_{2}$

$\mathrm{Ca}(\mathrm{acac})_{2} \cdot 2 \mathrm{H}_{2} \mathrm{O}$

$\mathrm{Sr}(\mathrm{acac})_{2} \cdot 2 \mathrm{H}_{2} \mathrm{O}$

$\mathrm{Ba}(\mathrm{acac})_{2} \cdot 2 \mathrm{H}_{2} \mathrm{O}$
292

284

291

293

294
273

$\underline{\log \mathcal{E}}$

4.0

4.3

4.3

4.4

4.4

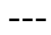

294

295

295

295

\section{4}

4.4

4.4

---

4.6

4.6

4.6

4.7

4.4

$295 \quad 4.6$

\footnotetext{
* Unstable
}

The proof for the hypothesis that hydrolysis indeed takes place was obtained through the following experiments: 
a) Plots of $\lambda_{\max } v s$. concentration for all anhydrous and hydrated compounds at various concentrations (except for beryllium and magnesium acetylacetonates which form no hydrates) leveled off at $273 \mathrm{m \mu}$, the observed maxima for $\mathrm{H}(\mathrm{acac})$ [a typical example is shown in Figure 5]. At the same time the value for the molar absorptivity also leveled off at 10,000 $1 \mathrm{~mole}^{-1} \mathrm{~cm}^{-1}$, the observed value for $\mathrm{H}$ (acac).

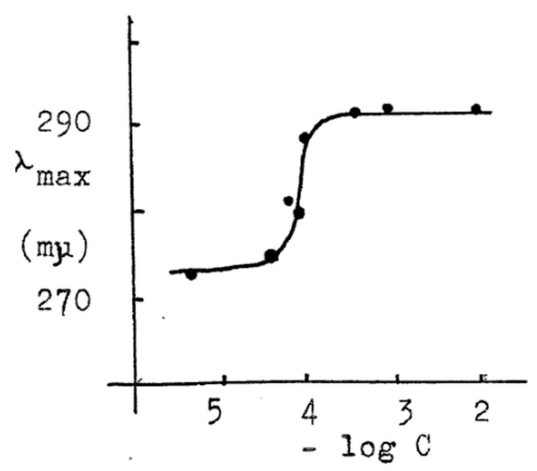

Figure 5. UV concentration study of $\mathrm{Li}(\mathrm{acac})$ in Absolute Alcohol.

b) Plots of $\log \varepsilon v s$. $\lambda_{\max }$ [a typical example is shown in Figure 6] for the anhydrous and hydrated compounds [again, except for the beryllium and magnesium species] show but one isosbestic point indicating the presence of just two absorbing species, ${ }^{[18]}$ presumably $\mathrm{M}(\mathrm{acac})_{\mathrm{n}}$ and $\mathrm{H}(\mathrm{acac})$. Solutions of $\mathrm{Be}(\mathrm{acac})_{2}$ and $\mathrm{Mg}(\mathrm{acac})_{2}$, which do not hydrolyze, have no isosbestic points.

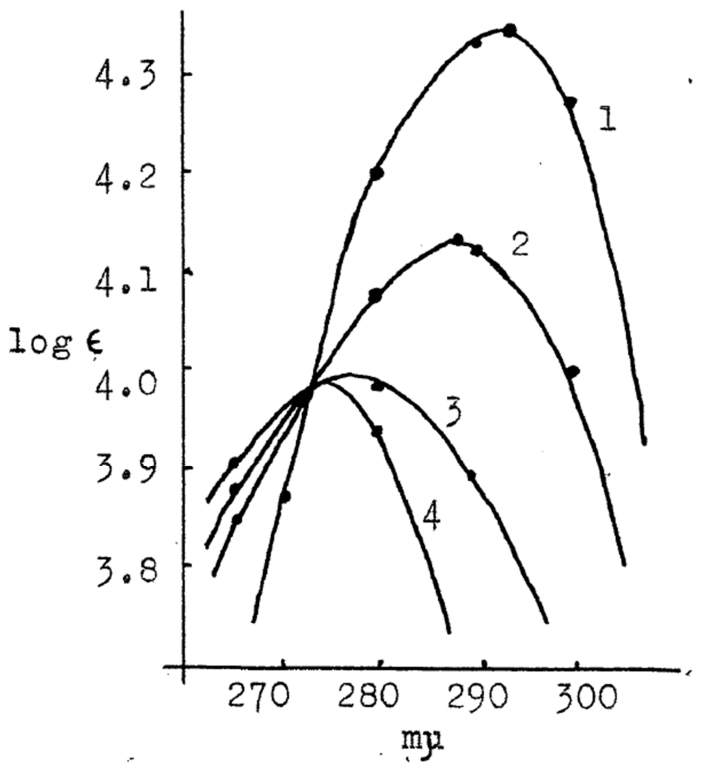

Figure 6. Extinction coefficient for $\mathrm{Li}(\mathrm{acac})$ in Absolute Ethanol at concentrations 1) $10^{-4} \mathrm{M}$; 2) $5 \times 10^{-5} \mathrm{M}$; 3) $10^{-5} \mathrm{M}$; 4) $10^{-6} \mathrm{M}$. 
c) When sodium-dried alcohol was used to prepare the solutions, plots of $\lambda_{\max } v s$. concentration gave straight horizontal lines at the $\lambda_{\max }$ levels characteristic of the corresponding compounds; however, when water was added to these solutions, the $\lambda_{\max }$ dropped back to the corresponding $273 \mathrm{~m} \mu$ in every case. See, for example, Figure 7.

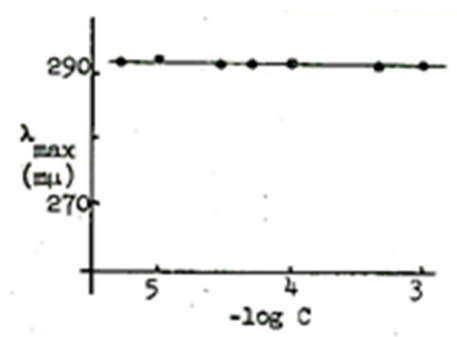

Figure 7. UV plot of $\lambda_{\max } v s$. concentration performed in sodium-dried absolute ethanol - here for beryllium acetylacetonate.

Dilute active metal acetylacetonate solutions dissociate, and, in the presence of water, the $\mathrm{acac}^{-}$ion then proceeds to hydrolize:

$$
\begin{gathered}
\mathrm{M}(\mathrm{acac})_{\mathrm{n}} \leftrightarrow \mathrm{M}^{+\mathrm{n}}+\mathrm{n} \mathrm{acac}^{-} \\
\mathrm{acac}^{-}+\mathrm{H}_{2} \mathrm{O} \leftrightarrow \mathrm{H}(\mathrm{acac})+\mathrm{OH}^{-}
\end{gathered}
$$

The extent of the latter reaction is a sensitive function of the hydrogen ion concentration; thus the formation of $\mathrm{H}(\mathrm{acac})$ could be enhanced by small amounts of carbon dioxide - even that provided from the breath:

$$
\begin{gathered}
\mathrm{CO}_{2}+\mathrm{H}_{2} \mathrm{O} \leftrightarrow \mathrm{H}_{2} \mathrm{CO}_{3} \leftrightarrow \mathrm{H}^{+}+\mathrm{HCO}_{3}^{-} \\
\mathrm{H}^{+}+\mathrm{acac}^{-} \leftrightarrow \mathrm{H}(\mathrm{acac})
\end{gathered}
$$

Data in Table II indicate that $\lambda_{\max }$ for the alkali metal complexes increases slightly from $\mathrm{Li}(\mathrm{acac})$ through $\mathrm{Cs}(\mathrm{acac})$ with the increase occurring between the lithium and sodium compounds. It is also evident that the trend in the values for $\lambda_{\max }$ for the alkaline earths metal acetylacetonates is not as regular as that for the alkali metal compounds. While efforts to correlate quantitatively the position of maximum absorption with structure have been generally unimpressive, a qualitative analysis of this relation is appropriate. It is well known that an increase in conjugation results in a red shift of $\lambda_{\max }{ }^{[6,18,19]}$ For the alkali and alkaline earth systems under investigation it is hard to conceive that conjugation should increase with increasing atomic number of the central element as the data in Table II might appear to imply. On electrostatic grounds, however, it would be expected that, as the size of the metal ion increases and its electronegativity decreases, the interaction of the ion with oxygen should also 
decrease. This would result in less distortion of the oxygen's $\pi$-orbitals and lead to an increased value of $\lambda_{\max }$ for the less perturbed anion. ${ }^{[19]}$

Thus, if the position of $\lambda_{\max }$ were mainly a function of the degree of benzenoid character of the chelate, the observed maximum should decrease as the size of the metal ion increases from $\mathrm{Li}^{+}$to $\mathrm{Cs}^{+}$. However, if the position of $\lambda_{\max }$ were mainly due to electrostatic interaction, then $\lambda_{\max }$ might be expected to increase as electrostatic interaction decreases from $\mathrm{Li}^{+}$to $\mathrm{Cs}^{+}$. The values of $\lambda_{\max }$ would seem to indicate comparable electrostatic interactions or almost identical M-O bonds for the acetylacetonates of sodium, potassium, rubidium, and cesium. For the alkaline earths, chelation appears to over-ride electrostatic interaction at beryllium; the $\lambda_{\max }$ for the calcium, strontium, and barium compounds reflects similar electrostatic interactions in the nature of their M-O bonds.

Most UV absorption curves obtained in these experiments are symmetrical, indicating the closeness of the respective $\lambda_{\max }$ for $\mathrm{M}(\mathrm{acac})_{\mathrm{n}}$, $\mathrm{acac}^{-}$, and $\mathrm{H}(\mathrm{acac}) . \mathrm{Mg}(\mathrm{acac})_{2}$ is an exception in that its absorption spectrum has a high-wavelength shoulder [see Figure 8]. Cotton ${ }^{[6]}$ has

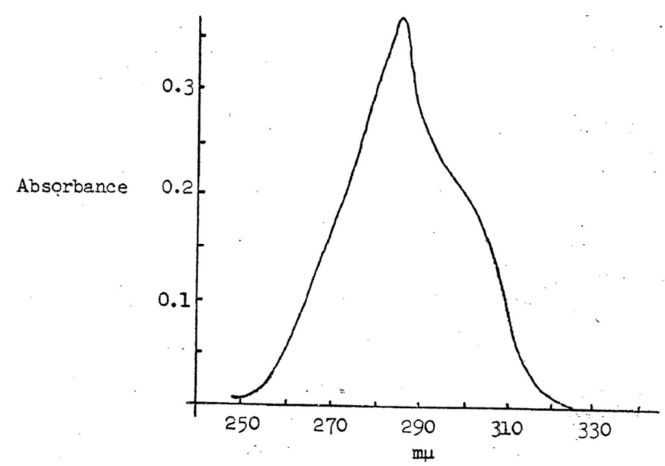

Figure 8. UV spectrum of $\left.1.0 \times 10^{-3} \mathrm{M} \mathrm{Mg(acac}\right)_{2}$ in Absolute Alcohol.

attributed such shoulders to possible $\pi-\pi *$ transitions although others ${ }^{[20]}$ have attributed their origin to intra-molecular ring interactions. The low energy shoulder in the spectrum for $\mathrm{Al}(\mathrm{acac})_{3}$, for example, is thought to be due to such interactions. ${ }^{[1]} \mathrm{A}$ similar argument may, of course, be used for the magnesium complex. Alternatively, it may be that an equilibrium exists between tetrahedral and distorted tetrahedral arrangements, or that $\mathrm{acac}^{-}$bonds to magnesium through only one of its potential coordinating oxygens. These possibilities are really not too surprising, since $\operatorname{Mg}(\mathrm{acac})_{2}$, being a borderline case, appears to have both benzenoid and salt-like characteristics.

\section{NMR Study}

NMR data have confirmed the results of our UV and IR studies. Experimentally it has been shown ${ }^{[\mathbf{6}, 13,14]}$ that for similar chelates (i.e., same chelating agent and same type of metal ion) a principal indicator of bond type is the position of the vinylic hydrogen $(=\mathrm{CH}-)$ resonance. [See Table IV and Figure 9]. 
Table IV: NMR data for Metal acetylacetonate solutions in methanol; PPM relative to tetramethylsilane.

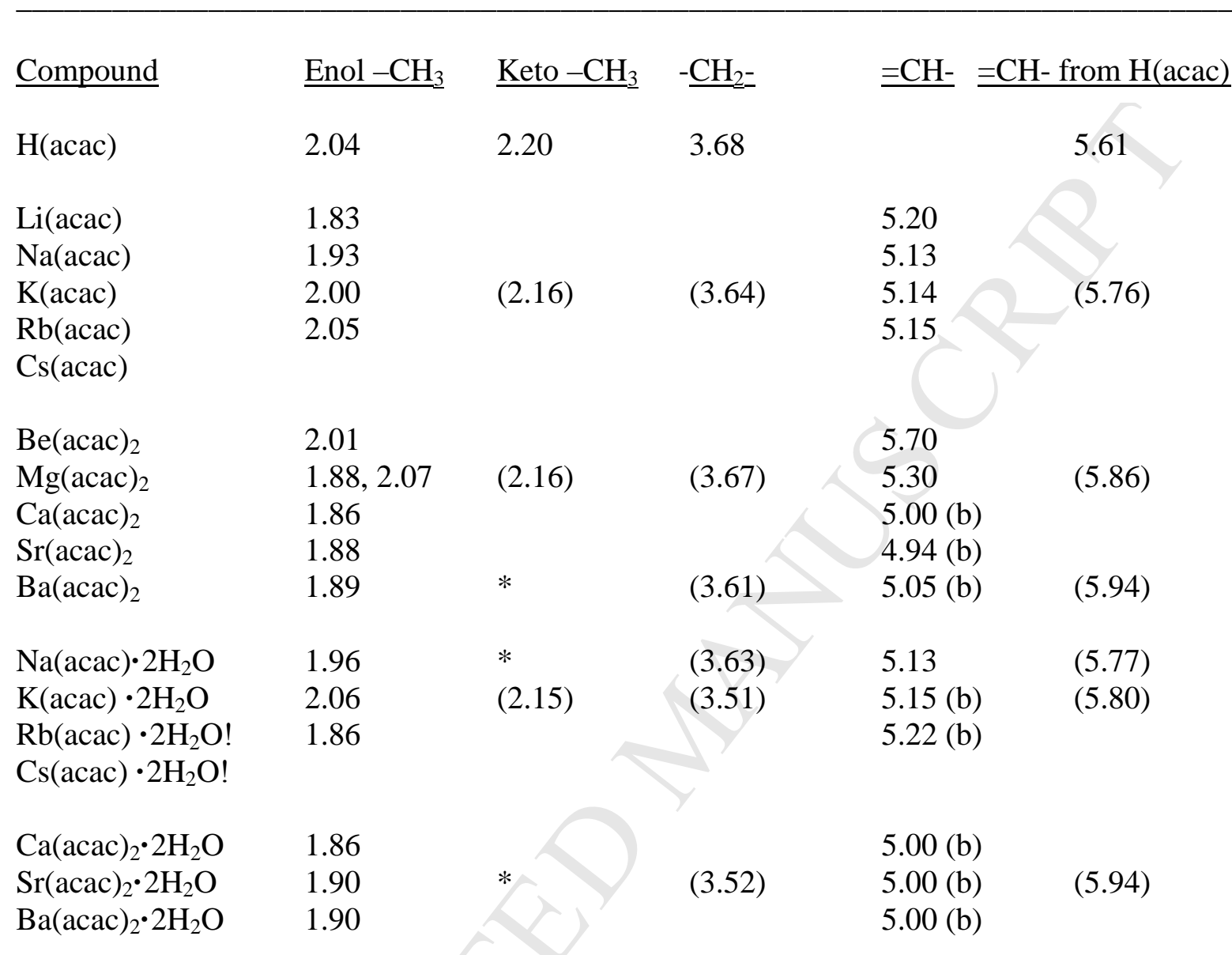

( ) Peaks appearing after solution has been heated.

* Peaks are buried under methanol side bands.

(b) Peaks are broad.

! Unstable. 


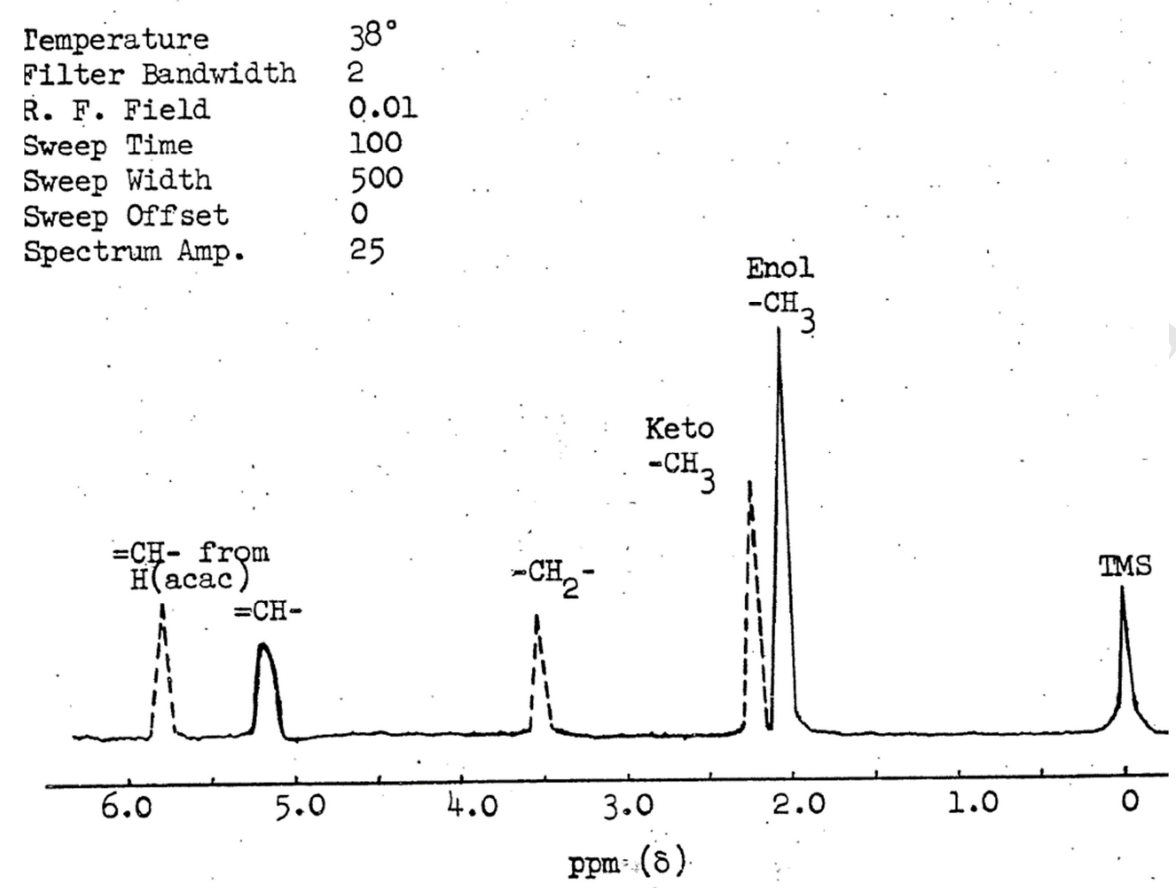

Figure 9. NMR spectrum of $\mathrm{K}(\mathrm{acac}) \cdot 2 \mathrm{H}_{2} \mathrm{O}$ in methanol. No solvent absorptions are shown. [Temperature: $38^{\circ}$; Filter Bandwidth 2; R. F. Field: 0.01; Sweep Time: 100; Sweep Width: 500; Sweep Offset: 0; Spectrum Amplitude: 25]

The hydrogen resonance peak shifts down field as the benzenoid-like properties of a chelate increase. In other words, the more the $\alpha$-hydrogen is deshielded the more its resonance shifts to lower energies. The vinylic hydrogen changes systematically with a change of the metal ion in the chelate. Thus we were able to correlate increasingly stronger ring currents with the shifting of the vinylic hydrogen peak to lower fields.

Our studies indicate that for anhydrous acetylacetonates the hydrogen absorption peak positions follow the order (by metal component and absorption in $\mathrm{ppm}$ ):

$$
\begin{aligned}
& \mathrm{Be}(5.70)>\mathrm{H}(5.61)>\mathrm{Mg}(5.30)>\mathrm{Li}(5.20)>\mathrm{Rb}(5.15) \sim \mathrm{K}(5.14) \sim \mathrm{Na}(5.13)> \\
& \mathrm{Ba}(5.05) \sim \mathrm{Ca}(5.00) \sim \mathrm{Sr}(4.94)
\end{aligned}
$$

Again, values for the compounds of the lighter metals are out of line compared with those for the heavier ones. Hydrated acetylacetonates show NMR absorptions essentially identical to those of the corresponding anhydrous ones; this confirms the findings of the UV studies.

Raban et al. ${ }^{[21]}$ have since confirmed our findings that lithium chelation with acetylacetonate is more favorable thatn sodium chelation. These researchers also demonstrated that lithium prefers to chelate with two acetylacetonate anions forming $\mathrm{Li}(\mathrm{acac})_{2}{ }^{-}$.

The NMR spectrum of $\mathrm{Mg}(\mathrm{acac})_{2}$ merits special attention. Eaton ${ }^{[22]}$ reports that two (supposedly methyl) hydrogen resonance peaks are detectable in this spectrum and interprets their presence as evidence for a non-symmetrical chelate structure for the magnesium compound. However, in our studies we could obtain these two peaks only under conditions which lead to partial hydrolysis of the starting compound. In light of our hydrolysis studies and the fact that it has been impractical to relate the $-\mathrm{CH}_{3}$ proton absorption to structure, ${ }^{[23]}$ we interpret the two 
absorption peaks as due simply to methyl hydrogen absorptions in $\operatorname{Mg}(\mathrm{acac})_{2}$ and its hydrolysis product, $\mathrm{H}(\mathrm{acac})$.

Clearly then, the $\operatorname{Mg}(\mathrm{acac})_{2}$ complex is different from the chelates of the lithium and beryllium complexes on the one hand, and the salt-like structures of the heavier metals on the other. Our observations point to an arrangement of the magnesium structure oscillating between a chelate and salt-like structure. This is further confirmed by the complexes behavior on temperature: at room temperature the open, salt-like structure predominates, whereas at lower temperature the chelate structure take precedence.

The temperature studies for $\operatorname{Mg}(\mathrm{acac})_{2}$ in methanol for temperatures at $40^{\circ} \mathrm{C}, 30^{\circ} \mathrm{C}, 0^{\circ} \mathrm{C}$, and $-40^{\circ} \mathrm{C}$ point to the existence of an equilibrium between two structures. As the temperature of this solution is lowered, the vinylic hydrogen absorption peak moves down field.
An explanation consistent with this shift of peaks must take into account an
equilibrium which is markedly temperature dependent. Such an equilibrium could
involve the opening and closing of the magnesium acetylacetonate ring or the
rearrangement between two geometrical forms. It would appear that at room temperature the open structure prevails since the vinylic hydrogen absorption peaks appears at higher field. At lower temperature the chelate form predominates as is evidenced by the low field position of the hydrogen resonance peak, as shown in Figure 10 below:

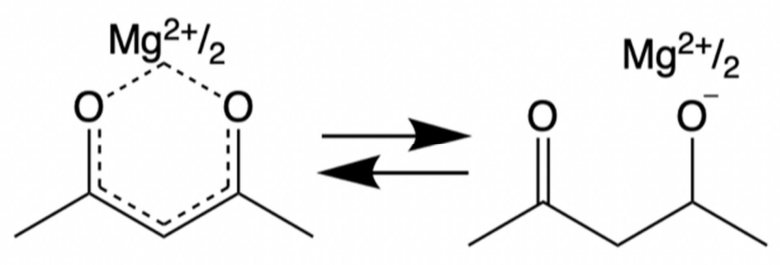

Low temperature High temperature

Figure 10. The oscillating structures of the $\mathrm{Mg}(\mathrm{acac})_{2}$ complex

A study on alcohols ${ }^{[18]}$ shows that hydrogen bonding causes -OH hydrogen absorptions to broaden as the temperature is lowered. It is quite possible that in the $\operatorname{Mg}(\mathrm{acac})_{2}$ system the vinylic hydrogen $(=\mathrm{CH}-)$ bonds to methanol via hydrogen bonding, and this tendency in enhanced by decreasing temperature. An increased $\mathrm{H} \cdot \cdots \mathrm{OH}$ interaction with decreased temperature would be consistent with the observed broadening of the vinylic hydrogen absorption peak.

\section{Experimental Section}

\section{Compound Preparation}

Most alkali and alkaline earth acetylacetonates were prepared following long-established procedures. ${ }^{[2,11,24]}$ Best results were obtained by allowing a direct reaction between alkali metal and acetylacetone in an inert solvent. Alkaline earth acetylacetonates were prepared via metathetical reactions. Thus, $\mathrm{Ba}(\mathrm{acac})_{2}$ was prepared by allowing $\mathrm{Ba}(\mathrm{OH})_{2}$ to react with acetylacetone in absolute ethanol. The hydrated species of acetylacetonates of sodium, 
potassium, rubidium, cesium, calcium, strontium, and barium were obtained through recrystallization of the anhydrous compound from $95 \%$ ethanol. Water analyses were carried out on those hydrated species not previously reported in the literature. The new compounds $\mathrm{Rb}(\mathrm{acac}) \cdot 2 \mathrm{H}_{2} \mathrm{O}$ and $\mathrm{Cs}(\mathrm{acac}) \cdot 2 \mathrm{H}_{2} \mathrm{O}$ were found to be extremely unstable and had to be prepared immediately prior to use. We were unable to prepare $\mathrm{Li}(\mathrm{acac}) \cdot 2 \mathrm{H}_{2} \mathrm{O}, \mathrm{Be}(\mathrm{acac})_{2} \cdot 2 \mathrm{H}_{2} \mathrm{O}$, or $\mathrm{Mg}(\mathrm{acac})_{2} \cdot 2 \mathrm{H}_{2} \mathrm{O}$.

\section{$\underline{\text { Instrumentation Used }}$}

IR spectra of the samples in $\mathrm{KBr}$ pellets were made using spectrophotometers Beckman IR-5, IR-10 and/or Perkin Elmer Infracord. Polystyrene was used as a standard, employing the $1601 \mathrm{~cm}^{-1}$ (6.24 microns) and $698.9 \mathrm{~cm}^{-1}$ (14.31 microns) absorptions as reference peaks.

UV spectra were made on a Cary 14 spectrophotometer using chart speed of $30 \mathrm{~m} \mu /$ inch and reducing this speed to $15 \mathrm{~m} \mu$ when a run was repeated for absorption maxima assignment. Standard concentrated stock solutions were prepared by weighing the required amount of solid and dissolving it in specially dried absolute ethanol. This solution was then used for the preparation of more dilute solutions. Matched $100 \mathrm{~mm}, 10 \mathrm{~mm}, 1 \mathrm{~mm}$, and $0.1 \mathrm{~mm}$ quartz cells were used throughout. U.S.I. reagent grade absolute alcohol ( $200^{\circ}$ proof) was used in the hydrolysis studies. This alcohol, referred to in this paper as 'absolute alcohol', was found to obtain $10^{-2} \mathrm{M}$ water. To obtain entirely dry alcohol, the above was treated with metallic sodium in a nitrogen atmosphere using a system provided with reflux, condenser, and air trap for removal of the required amount of solvent directly into the UV cells without exposure to air.

All NMR spectra were recorded on a Varian Associates A-60 Analytical NMR spectrometer at a frequency of 60 megacycles/second. Chemical shifts were observed in ppm relative to tetramethylsilane. Reagent grade absolute methanol and mono-deuteromethanol served as solvents.

\section{Summary and Conclusion}

We were able to definitively establish the nature of bonding for alkali and alkaline earth acetylacetonates. IR, UV, and NMR results all point to the fact that beryllium and lithium complexes are chelates, and, except magnesium, the rest are salt-like. IR studies show an abrupt change in bonding between lithium and beryllium complexes and the rest of the group elements. No distinguishing feature is evident for the magnesium complex. UV studies indicate an extreme sensitivity toward hydrolysis producing $\mathrm{H}(\mathrm{acac})$ and $\mathrm{M}(\mathrm{acac})_{\mathrm{n}}$. The magnesium complex is a bridged hybrid oscillating between benzenoid and salt structures. NMR studies confirm both the UV and IR studies. Temperature studies of the magnesium complex indicate salt features at higher temperatures whereas ring currents are observed as the temperature is lowered to $-40^{\circ} \mathrm{C}$. We found no chemical differences between hydrated and anhydrous species.

\section{Acknowledgements}

My (EB) thesis advisor, Professor Keller (student of John C. Bailar), and I worked on this paper for several years exchanging notes and revisions. Unfortunately, Dr. Keller passed away prematurely and I put the draft aside. It is my hope that this updated paper, serves as a welldeserved posthumous Festschrift, and does honor to a gentleman who trained me and scores of other students. 
My thanks go to Dr. Sara Dille who reworked and updated all graphs, and to Professor Partha Basu, IUPUI, for valuable discussions. Also a debt of gratitude to Eric A. Snajdr, science librarian at IUPUI, who spent considerable time reviewing the alkali and alkaline earth acetylacetonate literature for the recent decades to make sure that, to the best of our knowledge, no relevant work is missed.

\section{References}

[1] J. P. Fackler, Jr., Progress in Inorganic Chemistry (Ed.: F. A. Cotton), Interscience Publishers, New York, 1966, VII, p. 361.

[2] a) N. V. Sidgwick, F. M. Mercer, J. Chem. Soc. 1925, 127, 2379; b) N. V. Sidgwick, The Chemical Elements and Their Compounds, Clarendon Press, Oxford, 1950, I, p. 99; c) J. C. Bailar, Jr., D. H. Busch, Chemistry of the Coordination Compounds (Ed.: J. C. Bailar, Jr.), Reinhold Publishing Corporation, New York, 1956, p. 2.

[3] R. S. Rasmussen, D. D. Tunicliff, R. R. Brattain, J. Am. Chem. Soc. 1949, 71, 1068.

[4] H. W. Morgan, U.S Atomic Energy Commission Report, AECD 1949, 2659.

[5] a) K. Nakamoto, Infrared Spectra of Inorganic and Coordination Compounds, John Wiley and Sons, New York, 1963; b) S. F. Tayyari, T. Bakhshi, S. J. Mahdizadeh, S. Mehrani, R. E. Sammelson, J. Molecular Structure, 2009, 938, 76-81.

[6] a) M. Calvin, K. W. Wilson, J. Am. Chem. Soc. 1945, 67, 2003; b) R. H. Holm, F. A. Cotton, J. Am. Chem. Soc. 1958, 80, 5658.

[7] H. A. Szymanski, Progress in Infrared Spectroscopy, Plenum Press, New York, 1962, p. 44.

[8] K. Nakamoto, P. J. MacCarthy, A. E. Martell, Nature 1959, 183, 459.

[9] K. Nakamoto, A. E. Martell, J. Chem. Phys.1960, 32, 588.

[10] J. P. Dismukes, L. H. Jones, J. C. Bailar, Jr., J. Phys. Chem., 1961, 65, 792.

[11] G. T. Morgan, H. W. Moss, J. Chem. Soc. 1914, 1, 194.

[12] J. P. Collman, Reactions of Coordinated Ligands, American Chemical Society Press, Washington, D.C., p. 78.

[13] F. A. Cotton, G. Wilkinson, Advanced Inorganic Chemistry, Interscience Publishers, $2^{\text {nd }}$ edition, New York, 1966, p. 696.

[14] R. E. Hester, Chem. Inc., London, 1963, 1397.

[15] Walter Gordy, J. Chem. Phys., 1946, 14, 305.

[16] Gordy's Rule allows for calculation of the force constant, k, between two bonded systems:

$$
\mathrm{k}=1.67 \times \mathrm{N}\left\{\frac{\mathrm{N}_{\mathrm{a}} \times \mathrm{N}_{\mathrm{b}}}{\mathrm{d}^{2}}\right\}^{3 / 4}+0.30
$$

where $X_{a}$ and $X_{b}$ are the electronegativities of the bonding atoms (Pauling's values), $N$ is the bond order which is set equal to 1.00 for all cases (justified in reference 9), and $d$ is the bond distance as obtained by adding the covalent radii of the atoms in question.

[17] H. Fakheri, S. F. Tayyari, M. M. Heravi, A. Morsali, J. Molecular Structure 2017, 1150, 340.

[18] a) J. R. Dyer, Applications of Absorption Spectroscopy of Organic Compounds, Prentice Hall, Englewood Cliffs, 1965; b) R. S. Drago, Physical Methods in Inorganic Chemistry, Reinhold Publishing Corp., New York, 1965, 131. 
[19] J. Charette, G. Neirynck, P. Teysssié, J. Phys. Chem. 1961, 65, p. 735.

[20] L. S. Forster, J. Am. Chem. Soc. 1964, 87, 3001.

[21] a) M. Raban, G. Yamamoto, Inorg. Nucl. Chem. Letters 1976, 12, 949-951; b) M. Raban, E. A. Noe, G. Yamamoto, J. Am. Chem. Soc. 1976, 99, 6527-6531; c) M. Raban, D. P. Haritos, J. Am. Chem. Soc. 1979, 101, 5178-5182.

[22] D. R. Eaton, J. Am. Chem. Soc., 1965, 87, 3097.

[23] J. A. S. Smith, J. D. Thwaites, Discussions Faraday Soc. 1962, 34, 143.

[24] L. F. Hatch, G. Sutherland, J. Org. Chem. 1948, 13, 249. 


\section{Highlights}

- The bonding nature of alkali and alkaline earth acetylacetonate complexes has been established using IR, UV, and NMR spectroscopies.

- The heavier metal complexes show salt-like features.

- Li and Be complexes show definite chelate bonding.

- At room temperature the $\mathrm{Mg}$ complex is salt like, whereas at low temperature $\left(-40^{\circ} \mathrm{C}\right)$ it becomes a chelate. 